\title{
IL-8 and eNOS polymorphisms predict bevacizumab-based first line treatment outcomes in RAS mutant metastatic colorectal cancer patients
}

\author{
Mariantonietta Di Salvatore ${ }^{1}$, Filippo Pietrantonio ${ }^{2}$, Armando Orlandi ${ }^{1}$, Marzia \\ Del $\mathrm{Re}^{3}$, Rosa Berenato ${ }^{2}$, Ernesto Rossi ${ }^{1}$, Marta Caporale ${ }^{2}$, Donatella Guarino ${ }^{4}$, \\ Antonia Martinetti ${ }^{2}$, Michele Basso ${ }^{1}$, Roberta Mennitto ${ }^{2}$, Concetta Santonocito ${ }^{4}$, \\ Alessia Mennitto ${ }^{2}$, Giovanni Schinzari ${ }^{1}$, Ilaria Bossi ${ }^{2}$, Ettore Capoluongo ${ }^{4}$, Romano \\ Danesi $^{3}$, Filippo de Braud ${ }^{2}$, Carlo Barone ${ }^{1}$ \\ ${ }^{1}$ Unit of Clinical Oncology, Università Cattolica del Sacro Cuore, 00168 Rome, Italy \\ ${ }^{2}$ Medical Oncology Department, Fondazione IRCCS Istituto Nazionale dei Tumori, 20133 Milan, Italy \\ ${ }^{3}$ Clinical Pharmacology and Pharmacogenetic Unit, Department of Clinical and Experimental Medicine, University of Pisa, \\ 56126 Pisa, Italy \\ ${ }^{4}$ Laboratory of Clinical Molecular Biology, Institute of Biochemistry and Clinical Biochemistry, Università Cattolica del Sacro \\ Cuore, 00168 Rome, Italy
}

Correspondence to: Mariantonietta Di Salvatore, email: mariantonietta.disalvatore@gmail.com

Keywords: single nucleotid polymorphisms, bevacizumab, IL-8, eNOS, colorectal cancer

Received: May 23, 2016

Accepted: November 02, 2016

Published: January 25, 2017

\section{ABSTRACT}

Background: Predictive biomarkers of efficacy and toxicity of bevacizumab have not yet been validated. This study assessed the influence of IL-8, eNOS and VEGF-A polymorphisms in RAS mutated metastatic colorectal cancer patients receiving bevacizumab-based chemotherapy.

Methods: 120 patients treated with first-line combination FOLFOX6 plus bevacizumab were included. A historical cohort of 112 RAS mutated colorectal cancer patients treated with FOLFOX6 alone served as control group. The following SNPs were analyzed: IL-8 c.-251T >A; eNOS c.-786T $>C$ and c.-894G $>T$; VEGF-A c.936C $>T$, c. $958 \mathrm{~T}>\mathrm{C}$, C.1154A $>$ G and C.2578C $>$ A. Correlation of SNPs, baseline IL-8 serum levels and bevacizumab-efficacy was done.

Results: In the bevacizumab group, carriers of the IL-8 alleles c.-251TA+AA showed a shorter PFS $(P=0.002)$ and OS $(P=0.03)$ compared to TT alleles. Patients with pre-treatment IL-8 $<18.25 \mathrm{pg} / \mathrm{ml}$ showed significantly longer median PFS and OS (PFS: 10.9 vs 7.6 months, $P=0.005$; OS: 30.7 vs 18.2 months, $P<0.001$ ) compared to patients with IL-8 higher levels $(>18,25 \mathrm{pg} / \mathrm{ml})$. IL-8 c.-251TA+AA carriers had significantly higher IL-8 levels $(P<0.0001)$. Multivariate analysis confirmed association of IL-8 polymorphism with PFS, and of IL-8 baseline levels with both PFS and OS. IL-8 SNP did not affect the outcome in the control group. The eNOS polymorphism C.-894G $>T$ was found associated with higher severe toxicity $(P=0.0002)$ in patients carrying the c.-894TT genotype.

Conclusions: Although our data need prospective validation, IL-8 and eNOS SNPs may be have a role as predictive biomarkers for bevacizumab efficacy and toxicity.

\section{INTRODUCTION}

To date, predictive biomarkers of efficacy and toxicity of bevacizumab have not yet been validated in metastatic colorectal cancer (mCRC) patients [1]. Some evidence suggests that clinical or radiological parameters might predict the efficacy of bevacizumab, but their clinical implementation has yet to be proven 
[2-4]. The use of predictive biomarkers might improve mCRC patients selection for bevacizumab-based treatment. This issue is particularly relevant for $R A S$ mutated subset, due to limited availability of effective treatment options. Unfortunately, since angiogenesis is a multifactorial and host-mediated process, validation of such biomarkers is not always easy. The outcome of patients treated with bevacizumab-based therapies may be related to polymorphisms in genes involved in different aspects of angiogenesis, leading to changes in vascular endothelial growth factor (VEGF)-dependent and independent pathways. A role of VEGF single nucleotide polymorphisms (SNPs) has been suggested in colorectal cancer with controversial results $[5,6]$.

While VEGF-A is the target of bevacizumab, it is conceivable that resistance to treatment may also be linked to an angiogenic switch due to up-regulation of VEGF-independent pathways. For instance, interleukin-8 (IL-8) induces angiogenesis and increases endothelial permeability in absence of hypoxic environment [7-10]. The IL-8 c.-251T > A polymorphism seems to be associated to variations of promoter transcriptional activity and to higher levels of circulating IL-8 [11-15]. Moreover, VEGF up-regulate the expression of nitric oxide synthase [16, 17], resulting in the release of endothelium-derived nitric oxide and in the consequent stimulation of angiogenesis [18-21]. While the activation of VEGFR signaling pathway stimulates the eNOS leading to the production of the potent vasodilator nitric oxide, the inhibition of VEGF signaling might lead to decrease the nitric oxide concentrations, resulting in vasoconstriction. In fact, the eNOS polymorphisms were found to be associated to a higher risk of developing grade 3 hypertension in a group of patients treated with sunitinib [22]. However, in literature there are few and uncertain data regarding the eNOS role in bevacizumab-induced toxicity.

This study was aimed at exploring the role of SNPs in IL-8 (c.-251T $>$ A), eNOS (c.-786T $>$ C, c.-894G $>$ T) and VEGF-A (c.936C $>$ T, c. $958 \mathrm{C}>\mathrm{T}$, c. $1154 \mathrm{~A}>\mathrm{G}$, c. $2578 \mathrm{C}>\mathrm{A}$ ) as potential biomarkers of efficacy and toxicity of bevacizumab in $R A S$ mutated mCRC. Moreover, it was evaluated the correlation of SNPs, IL-8 serum levels and bevacizumab efficacy.

\section{RESULTS}

\section{Study population}

One-hundred and twenty consecutive patients were enrolled from 2007 to 2010 in the bevacizumab group, and their clinical characteristics are reported in Table 1. Forty-seven (39.2\%) patients experienced a partial response and $8(6.6 \%)$ a complete response, while 53 $(44.2 \%)$ had a stable disease and $12(10 \%)$ had a PD. ORR was $45.8 \%$, median PFS and median OS were 10 and 37.6 months, respectively. Among the main clinical characteristics, only the number of metastatic sites showed a statistically significant correlation both with PFS and OS in the univariate analysis. In particular, patients with $>2$ metastatic sites had a PFS and an OS significantly shorter (PFS: 6 vs 9.2 months, HR: 2.31, 95\% CI 1.729.09, $\mathrm{P}=0.001$; OS: 19.6 vs 29 months, HR: $2.77,95 \%$ CI 2.27-12.5, $\mathrm{P}<0.001)$ compared to those with $<2$ metastatic sites. Considering only grade 3-4 toxicities, $11(9.1 \%)$ patients developed hypertension, 3 (2.5\%) bleeding, 3 $(2.5 \%)$ proteinuria, $3(2.5 \%)$ venous thromboembolism, 1 $(0.8 \%)$ arterial thromboembolism and $1(0.8 \%)$ acute renal failure.

Baseline characteristics of patients included in the control group are summarized in Table 2. Among the available clinical and pathological characteristics, only the number of metastatic sites showed a statistically significant correlation with OS in the univariate analysis (HR: $1.97,95 \%$ CI 1.11-2.42, $\mathrm{P}=0.04$ ). No significant correlation was found with PFS.

\section{Correlation between genotypes and treatment outcomes}

The genotyping analysis showed that all the SNPs were in Hardy-Weinberg Equilibrium and the relative frequencies of the selected and analysed SNPs are reported in Table 1 for bevacizumab group and in Table 2 for control group.

In the bevacizumab group, no statistically significant correlation was found between all analysed SNPs and ORR. Median PFS was significantly longer inpatients with IL-8 c.-251TT genotype as compared to those carrying the c.-251TA/AA genotypes (10 vs 8.2 months, HR: $0.53,95 \%$ CI $0.34-0.78, \mathrm{P}=0.002$ ) (Figure $1 \mathrm{~A}$ and Table 1); OS was also significantly longer inpatients with IL-8 c. $-251 \mathrm{TT}$ versus c. $-251 \mathrm{TA} / \mathrm{TT}$ (33 vs 26.3 months, HR: $0.64,95 \%$ CI 0.43-0.97, $\mathrm{P}=0.03$ ) (Figure 1B and Table 1). Patients with eNOS c.-251TG/GG genotype showed a significant lower PFS as compared to those carrying the c.-894TT genotype (9 vs 10 months, HR: 1.78, 95\% CI 1.01-3.12; $\mathrm{P}=0.049$ ), but did not show a significantly worse OS (27 vs 37 months, HR: $1.34,95 \%$ CI $0.78-$ 2.23; $\mathrm{P}=0.2$ ) (Table 1). All the other analyzed VEGF and eNOS SNPs failed to show any significant correlation with bevacizumab efficacy (Table 1).

The multivariate analysis was performed only with the significant clinical variable at the univariate analysis, i.e. number of metastatic sites. IL-8 c.-251AA/ AT genotype and presence of $>2$ metastatic sites retained their significant association with worse PFS $(\mathrm{P}=0.0006$, HR: $1.8,95 \%$ CI $1.18-2.8$; and $\mathrm{P}=0.015$, HR: $1.8,95 \% \mathrm{CI}$ $1.12-2.9)$, while only the presence of $>2$ metastatic sites was independently associated with OS ( $\mathrm{P}<0.001, \mathrm{HR}: 2.4$, $95 \%$ CI 1.44-.4.28). The eNOS c-894TT genotype was no longer associated with PFS. 
Table 1: Patients and disease characteristics in bevacizumab-treated group

\begin{tabular}{|c|c|c|c|c|c|c|c|c|c|}
\hline \multirow{2}{*}{ Characteristics } & & \multirow{2}{*}{$\begin{array}{c}N \\
120\end{array}$} & \multirow{2}{*}{$\%$} & \multicolumn{3}{|c|}{ Progression Free Survival } & \multicolumn{3}{|c|}{ Overall Survival } \\
\hline & & & & HR & $95 \% \mathrm{CI}$ & $\mathbf{P}$ & HR & $95 \% \mathrm{CI}$ & $\mathbf{P}$ \\
\hline \multirow[t]{2}{*}{ Age, years } & $\leq 65$ & 58 & 48.3 & & & & & & \\
\hline & $>65$ & 62 & 51.7 & 1.30 & $0.87-2.29$ & 0.59 & 1.27 & $0.67-2.75$ & 0.55 \\
\hline \multirow[t]{2}{*}{ Sex } & Male & 74 & 61.7 & & & & & & \\
\hline & Female & 46 & 38.3 & 0.91 & $0.79-1.26$ & 0.70 & 1.02 & $0.82-1.40$ & 0.79 \\
\hline \multirow[t]{2}{*}{ PS (ECOG) } & $0-1$ & 113 & 94.2 & & & & & & \\
\hline & 2 & 7 & 5.8 & 1.35 & $0.79-1.91$ & 0.68 & 1.47 & $0.85-2.21$ & 0.65 \\
\hline \multirow[t]{2}{*}{ Primary tumor site } & $\begin{array}{l}\text { Right } \\
\text { colon }\end{array}$ & 68 & 56.6 & & & & & & \\
\hline & $\begin{array}{l}\text { Left } \\
\text { colon }\end{array}$ & 52 & 43.4 & 0.61 & $0.39-1.13$ & 0.11 & 0.65 & $0.38-1.52$ & 0.37 \\
\hline \multirow[t]{2}{*}{$\begin{array}{l}\text { Previous adjuvant } \\
\text { treatment }\end{array}$} & No & 84 & 70.5 & & & & & & \\
\hline & Yes & 36 & 29.5 & 1.85 & $0.98-2.91$ & 0.06 & 1.34 & $0.73-2.56$ & 0.59 \\
\hline \multirow[t]{2}{*}{$\begin{array}{l}\text { N. of metastatic } \\
\text { sites }\end{array}$} & $\leq 2$ & 17 & 14.2 & & & & & & \\
\hline & $>2$ & 103 & 85.8 & 2.31 & $1.72-9.09$ & 0.001 & 2.77 & $2.27-12.5$ & $<0.001$ \\
\hline \multirow[t]{2}{*}{ Mucinous histotype } & No & 101 & 84.2 & & & & & & \\
\hline & Yes & 19 & 15.8 & 1.71 & $0.85-3.38$ & 0.12 & 2.23 & $0.91-3.31$ & 0.10 \\
\hline IL-8-251 T>A & TT & 43 & 36 & & & & & & \\
\hline \multirow[t]{2}{*}{ rs4073 } & TA & 50 & 42 & & & & & & \\
\hline & $\mathrm{AA}$ & 27 & 22 & & & & & & \\
\hline $\begin{array}{l}\text { TT+TA vs AA } \\
\text { (recessive model) }\end{array}$ & & & & 0.7 & $0.39-1.10$ & 0.12 & 0.70 & $0.47-1.27$ & 0.39 \\
\hline $\begin{array}{l}\text { TT vs TA+AA } \\
\text { (dominant model) }\end{array}$ & & & & 0.53 & $0.34-0.78$ & 0.002 & 0.64 & $0.43-0.97$ & 0.03 \\
\hline eNOS c.-786 $T>C$ & $\mathrm{TT}$ & 33 & 27.5 & & & & & & \\
\hline \multirow[t]{2}{*}{ rs2070744 } & $\mathrm{TC}$ & 60 & 50 & & & & & & \\
\hline & $\mathrm{CC}$ & 27 & 22.5 & & & & & & \\
\hline $\begin{array}{l}\text { TT+TC vs CC } \\
\text { (recessive model) }\end{array}$ & & & & 1.08 & $0.68-1.70$ & 0.70 & 0.98 & $0.60-1.50$ & 0.96 \\
\hline $\begin{array}{l}\text { TT vs TC+CC } \\
\text { (dominant model) }\end{array}$ & & & & 1.3 & $0.85-2.20$ & 0.2 & 0.92 & $0.59-1.43$ & 0.73 \\
\hline eNOS c. $-894 G>T$ & GG & 40 & 33 & & & & & & \\
\hline \multirow[t]{2}{*}{ rs1799983 } & GT & 64 & 54 & & & & & & \\
\hline & $\mathrm{TT}$ & 16 & 13 & & & & & & \\
\hline $\begin{array}{l}\text { GG+GT vs TT } \\
\text { (recessive model) }\end{array}$ & & & & 1.78 & $1.01-3.12$ & 0.049 & 1.34 & $0.78-2.23$ & 0.28 \\
\hline
\end{tabular}

(Continued) 


\begin{tabular}{|c|c|c|c|c|c|c|c|c|c|}
\hline \multirow{2}{*}{ Characteristics } & & \multirow{2}{*}{$\begin{array}{c}N \\
120\end{array}$} & \multirow{2}{*}{$\%$} & \multicolumn{3}{|c|}{ Progression Free Survival } & \multicolumn{3}{|c|}{ Overall Survival } \\
\hline & & & & HR & $95 \%$ CI & $\mathbf{P}$ & HR & $95 \% \mathrm{CI}$ & $\mathbf{P}$ \\
\hline $\begin{array}{l}\text { GG vs GT+TT } \\
\text { (dominant model) }\end{array}$ & & & & 1.11 & $1.70-1.72$ & 0.56 & 1.15 & $0.75-1.77$ & 0.50 \\
\hline $\begin{array}{l}\text { VEGF-A } \\
\text { c. } 936 C>T^{*}\end{array}$ & $\mathrm{CC}$ & 43 & 61.4 & & & & & & \\
\hline \multirow[t]{2}{*}{ rs3025039 } & $\mathrm{CT}$ & 25 & 35.7 & & & & & & \\
\hline & $\mathrm{TT}$ & 2 & 2.9 & & & & & & \\
\hline $\begin{array}{l}\text { CC }+ \text { CT vs TT } \\
\text { (recessive model) }\end{array}$ & & & & 1.04 & $0.25-4.35$ & 0.955 & 1.39 & $0.23-7.96$ & 0.74 \\
\hline $\begin{array}{l}\text { CC vs CT + TT } \\
\text { (dominat model) }\end{array}$ & & & & 1.38 & $0.35-5.38$ & 0.642 & 1.60 & $0.27-8.47$ & 0.64 \\
\hline $\begin{array}{l}\text { VEGF-A } \\
\text { c.958C }>T^{*}\end{array}$ & TT & 43 & 61.4 & & & & & & \\
\hline \multirow[t]{2}{*}{ rs833061 } & $\mathrm{TC}$ & 14 & 20 & & & & & & \\
\hline & $\mathrm{CC}$ & 13 & 18.6 & & & & & & \\
\hline $\begin{array}{l}\text { CC + CT vs TT } \\
\text { (recessive model) }\end{array}$ & & & & 1.54 & $0.73-3.27$ & 0.25 & 1.32 & $0.43-4.56$ & 0.57 \\
\hline $\begin{array}{l}\text { CC vs CT + TT } \\
\text { (dominat model) }\end{array}$ & & & & 1.03 & $0.51-2.12$ & 0.92 & 1.21 & $0.41-3.40$ & 0.72 \\
\hline $\begin{array}{l}\text { VEGF-A } \\
\text { c. } 1154 \mathrm{~A}>\mathrm{G}^{*}\end{array}$ & AA & 32 & 45.7 & & & & & & \\
\hline \multirow[t]{2}{*}{ rs1570360 } & $\mathrm{AG}$ & 28 & 40 & & & & & & \\
\hline & GG & 10 & 14.3 & & & & & & \\
\hline $\begin{array}{l}\text { AA + AG vs GG } \\
\text { (recessive model) }\end{array}$ & & & & 1.83 & $0.86-3.45$ & 0.07 & 1.81 & $0.85-3.12$ & 0.11 \\
\hline $\begin{array}{l}\text { AA vs AG + GG } \\
\text { (dominat model) }\end{array}$ & & & & 1.23 & $0.75-1.32$ & 0.45 & 1.32 & $0.65-1.36$ & 0.56 \\
\hline $\begin{array}{l}\text { VEGF-A } \\
\text { c. } 2578 C>A^{*}\end{array}$ & $\mathrm{CC}$ & 23 & 32.8 & & & & & & \\
\hline \multirow[t]{2}{*}{ rs699947 } & $\mathrm{CA}$ & 35 & 50 & & & & & & \\
\hline & $\mathrm{AA}$ & 12 & 17.2 & & & & & & \\
\hline $\begin{array}{l}\text { CC + CA vs AA } \\
\text { (recessive model) }\end{array}$ & & & & 1.09 & $0.64-1.93$ & 0.78 & 1.31 & $0.58-2.99$ & 0.55 \\
\hline $\begin{array}{l}\text { CC vs CA + AA } \\
\text { (dominant model) }\end{array}$ & & & & 1.15 & $0.55-2.23$ & 0.69 & 1.39 & $0.48-3.89$ & 0.544 \\
\hline
\end{tabular}

Association of clinical and genomic characteristics with PFS and OS in bevacizumab group.

Bold: Clinical and SNPs characteristics. Italic and bold: statistical significant value.

*: Evaluated only in cohort 1 (Policlinico "Gemelli").

Given the independent prognostic value of IL-8 c.-251T $>$ A, we assessed only this SNP in the historical control group of patients treated with FOLFOX only. No significant association with PFS or OS was detected (Figure 2A-2B), thus suggesting a potential predictive role of IL-8 SNP in patients treated we bevacizumab-based therapy.
Regarding toxicity, patients carrying the eNOS c.894TT genotype showed a statistically significant higher occurrence of hypertension and proteinuria when compared with GG + GT genotypes $(\mathrm{P}=0.0002)$ (Table 3). All analyzed VEGF SNPs, IL-8 c.-251T $>$ A and eNOS c. $-786 \mathrm{~T}>\mathrm{C}$ failed to show any significant correlation with toxicity (Table 3 ). 
Table 2: Patients and disease characteristics in the control group (non-bevacizumab treated)

\begin{tabular}{|c|c|c|c|c|c|c|c|c|c|}
\hline \multirow{2}{*}{ Characteristics } & & \multirow{2}{*}{$\begin{array}{c}\mathrm{N} \\
112\end{array}$} & \multirow{2}{*}{$\%$} & \multicolumn{3}{|c|}{ Progression Free Survival } & \multicolumn{3}{|c|}{ Overall Survival } \\
\hline & & & & HR & $95 \% \mathrm{CI}$ & $\mathbf{P}$ & HR & $95 \% \mathrm{CI}$ & $\mathbf{P}$ \\
\hline \multirow[t]{2}{*}{ Age, years } & $\leq 65$ & 50 & 44.6 & & & & & & \\
\hline & $>65$ & 62 & 55.4 & 1.2 & $0.71-2.11$ & 0.51 & 1.23 & $0.61-2.72$ & 0.52 \\
\hline \multirow[t]{2}{*}{ Sex } & Male & 58 & 51.7 & & & & & & \\
\hline & Female & 54 & 48.3 & 0.96 & $0.60-1.20$ & 0.62 & 1.12 & $0.62-2.40$ & 0.69 \\
\hline \multirow[t]{2}{*}{ PS (ECOG) } & $0-1$ & 102 & 91 & & & & & & \\
\hline & 2 & 10 & 9 & 1.15 & $0.66-2.10$ & 0.66 & 1.77 & $0.86-3.21$ & 0.43 \\
\hline \multirow[t]{2}{*}{ Primary tumor site } & $\begin{array}{l}\text { Right } \\
\text { colon }\end{array}$ & 62 & 55.3 & & & & & & \\
\hline & $\begin{array}{l}\text { Left } \\
\text { colon }\end{array}$ & 50 & 44.7 & 0.69 & $0.39-1.23$ & 0.18 & 0.65 & $0.29-1.61$ & 0.37 \\
\hline \multirow[t]{2}{*}{ Previous adjuvant } & No & 79 & 70.5 & & & & & & \\
\hline & Yes & 33 & 29.5 & 1.91 & $0.97-3.11$ & 0.06 & 1.25 & $0.67-2.91$ & 0.61 \\
\hline \multirow[t]{2}{*}{$\begin{array}{l}\text { N. of metastatic } \\
\text { sites }\end{array}$} & $\leq 2$ & 17 & 14.1 & & & & & & \\
\hline & $>2$ & 95 & 95.9 & 1.45 & $0.89-2.34$ & 0.41 & 1.97 & $1.11-2.42$ & 0.04 \\
\hline \multirow[t]{2}{*}{ Mucinous histotype } & No & 98 & 87.5 & & & & & & \\
\hline & Yes & 14 & 13.5 & 1.95 & $0.95-3.78$ & 0.08 & 2.45 & $0.97-3.91$ & 0.09 \\
\hline IL-8-251 T>A & TT & 38 & 33.9 & & & & & & \\
\hline \multirow[t]{2}{*}{ rs4073 } & $\mathrm{TA}$ & 45 & 40.1 & & & & & & \\
\hline & $\mathrm{AA}$ & 29 & 26 & & & & & & \\
\hline $\begin{array}{l}\text { TT+TA vs AA } \\
\text { (recessive model) }\end{array}$ & & & & 0.91 & $0.82-1.15$ & 0.71 & 0.88 & $0.79-1.23$ & 0.69 \\
\hline $\begin{array}{l}\text { TT vs TA+AA } \\
\text { (dominant model) }\end{array}$ & & & & 0.95 & $0.87-1.11$ & 0.66 & 0.87 & $0.84-1.12$ & 0.64 \\
\hline
\end{tabular}

Association of clinical and genomic characteristics with PFS and OS in control group.

Bold: clinical and SNPs characteristics. Italic and bold: statistical significant value.

\section{Functional significance of IL-8 c.251T $>$ A for IL-8 serum levels}

The median IL-8 serum level was $17 \mathrm{pg} / \mathrm{mL}$ (range 1.3-309.1 $\mathrm{pg} / \mathrm{mL}$ ). Using the ROC curve analysis, the baseline IL-8 serum level cut-off was $18.25 \mathrm{pg} / \mathrm{mL}$ (area under the curve 0.71 , Figure 3 ), which was quite similar to the median value. For this reason, patients showing a pre-treatment IL- 8 serum level $>18.25$ were classified as IL-8-high, and patients with pre-treatment level lower than 18.25 as IL-8-low. Median PFS and OS was significantly longer inIL-8-low patients as compared to IL-8-high patients (PFS: 10.9 vs 7.6 months, HR: 0.46, 95\% CI 0.2$0.76, \mathrm{P}=0.005$; OS: 30.7 vs 18.2 months, HR: $0.35,95 \%$ CI $0.13-0.52, \mathrm{P}<0.001$; Figure $4 \mathrm{~A}$ and $4 \mathrm{~B}$, respectively).
At the multivariate analysis including number of metastatic sites, only IL-8 levels $>18.25 \mathrm{pg} / \mathrm{mL}$ had an independent association with worse PFS ( $\mathrm{P}=0.0014$, HR: $2.9,95 \%$ CI 1.53-5.75) and $\mathrm{OS}(\mathrm{P}=0.0002$, HR: $3.2,95 \%$ CI 1.7-5.9). Most importantly, serum levels of IL-8 in patients with IL-8 c.-251 TT genotype (median level 4.7 $\mathrm{pg} / \mathrm{mL}$ ) was statistically lower as compared to those with TA (median level $29.3 \mathrm{pg} / \mathrm{mL}$ ) or AA genotypes (median level $32.2 \mathrm{pg} / \mathrm{ml})(\mathrm{H}: 17.0$, DF: $1 \mathrm{P}<0.0001)$. Interestingly, in a parallel cohort of 50 healthy volunteers enrolled in the two Institutions as controls, the median IL-8 level was 4 $\mathrm{pg} / \mathrm{mL}$ (range 1.5-35.7 pg/mL) and presence of IL-8 SNP was not correlated with variations of serum levels (H: 3.4, DF: $1, \mathrm{P}=0.67$ ). 


\section{DISCUSSION}

Several data on angiogenesis-related SNPs as predictive biomarkers of bevacizumab-based treatment were obtained from retrospective series and mostly involved VEGF [23]. For instance, VEGF c.-1498 TT SNP was associated with shorter PFS in mCRC patients treated with first-line FOLFIRI and bevacizumab [5]. However, a subsequent prospective validation study failed to confirm this hypothesis [6]. In line with these data, our study failed to show any significant impact of VEGF-A c. $936 \mathrm{C}>\mathrm{T}$, c. $958 \mathrm{~T}>\mathrm{C}$, c. $2578 \mathrm{C}>\mathrm{A}$ and c. $1154 \mathrm{~A}>\mathrm{G}$. This study was aimed at showing whether SNPs related to VEGF-independent pathways might influence the efficacy of bevacizumab-based treatment in patients with $R A S$ mutated mCRC. We focused on $R A S$ mutated tumors since recent retrospective analyses of randomized trials seem to suggest a relatively smaller benefit from antiangiogenic agents in this patients' subgroup with limited treatment options $[24,25]$. Thus, the discovery of predictive biomarkers of efficacy of antiangiogenic treatments in this patient population is an unmet clinical need. It is well known that IL-8 can induce an angiogenic switch [7-10], allowing the "escape" from VEGF-targeted treatment [26]. We showed for the first time that the IL-8 polymorphism c.-251 "A" allele (dominant model) was associated with significantly shorter PFS and OS. The multivariate model confirmed an independent correlation with PFS
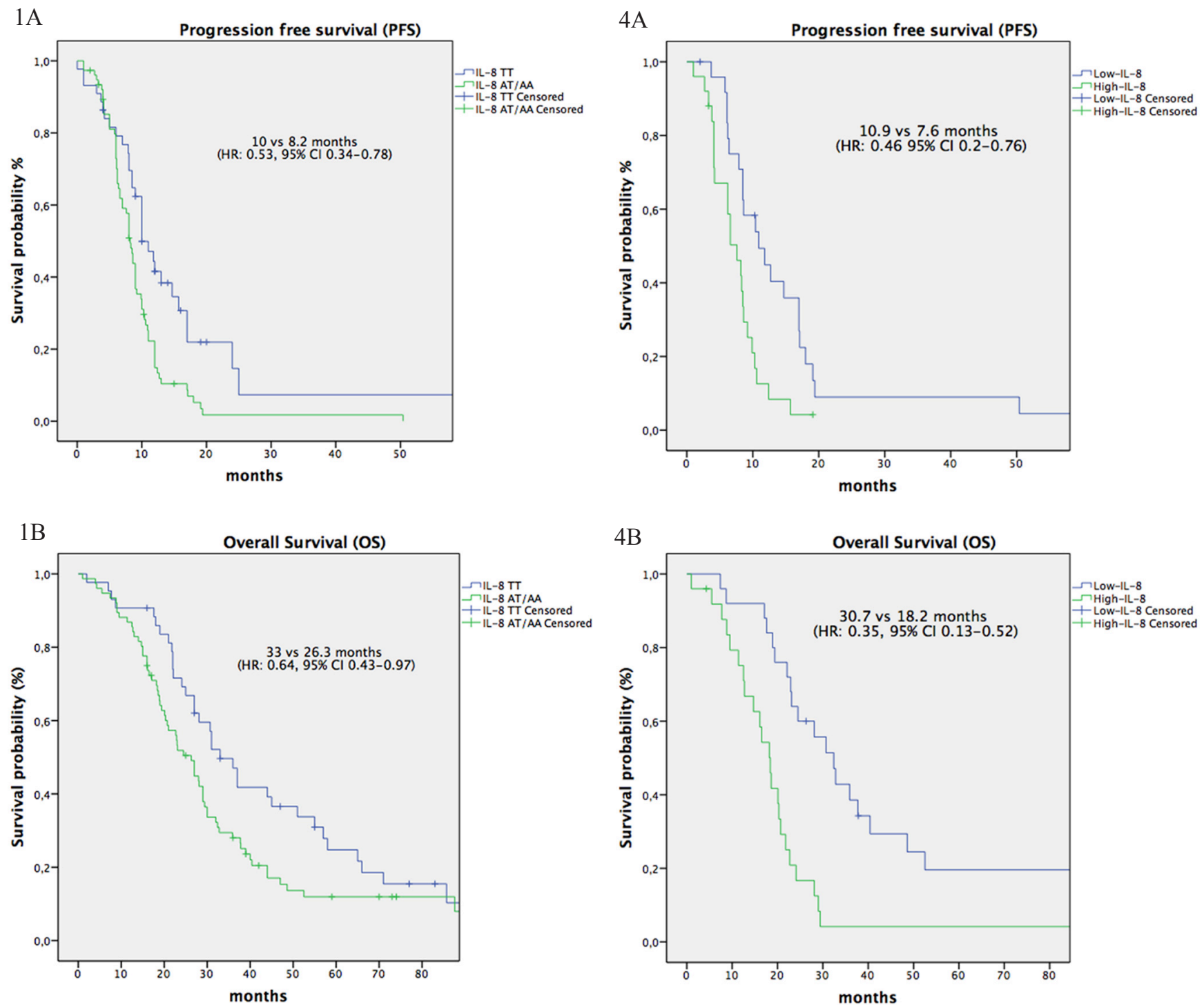

Multipanel Figure: IL-8 SNPs and IL-8 serum levels influence PFS and OS. Kaplan-Meier plots for PFS in patients with IL-8 TT genotype versus heterozygous TA and polymorphic homozygous AA genotypes 1A. and in patients with IL-8-low serum level versus IL-8-high serum levels 4A. Kaplan-Meier plots for OS in patients with IL-8 TT genotype versus heterozygous TA and polymorphic homozygous AA genotypes 1B. and in patients with IL-8-low serum level versus IL-8-high serum levels 4B. 
A

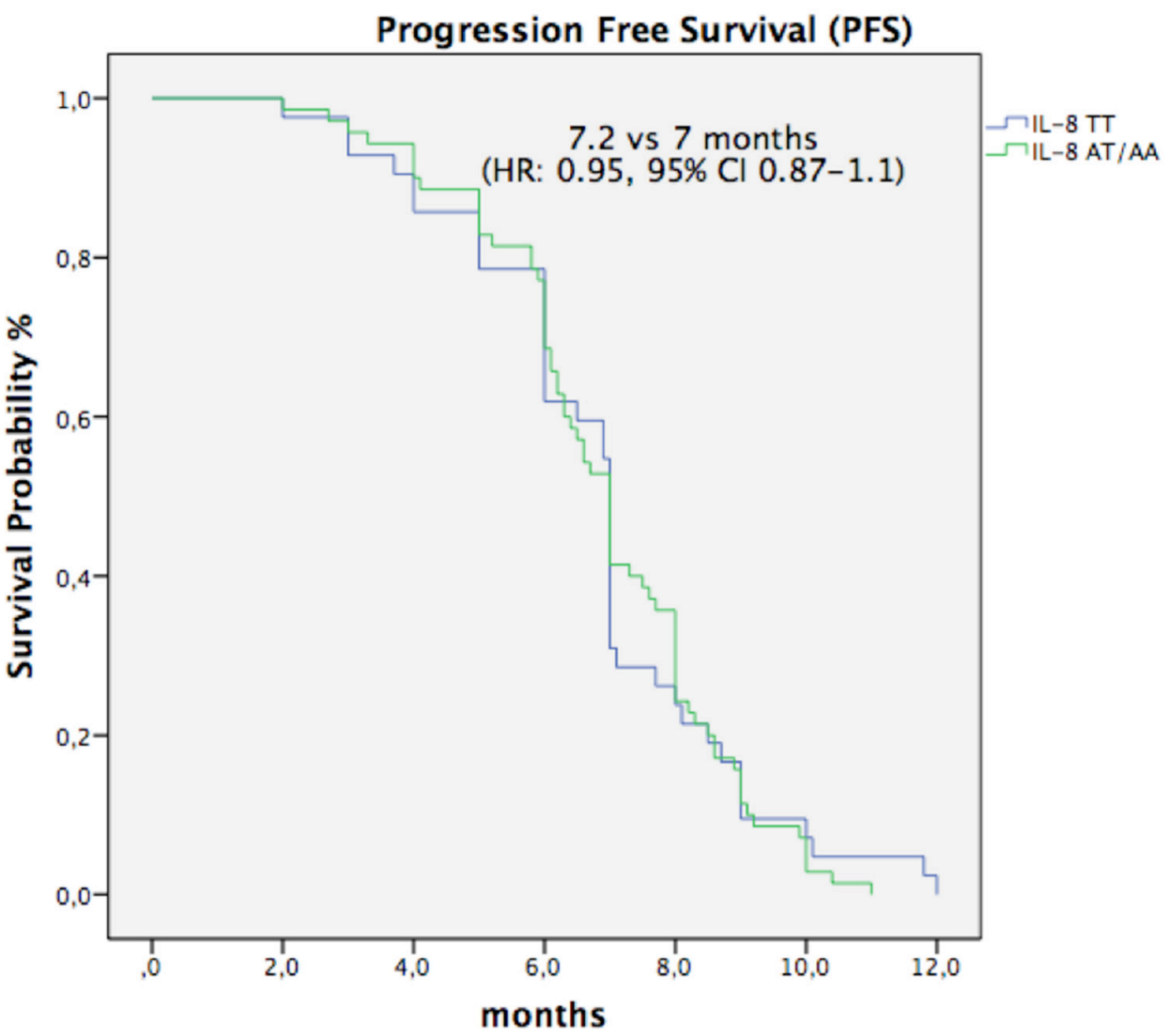

B

Overall Survival (OS)

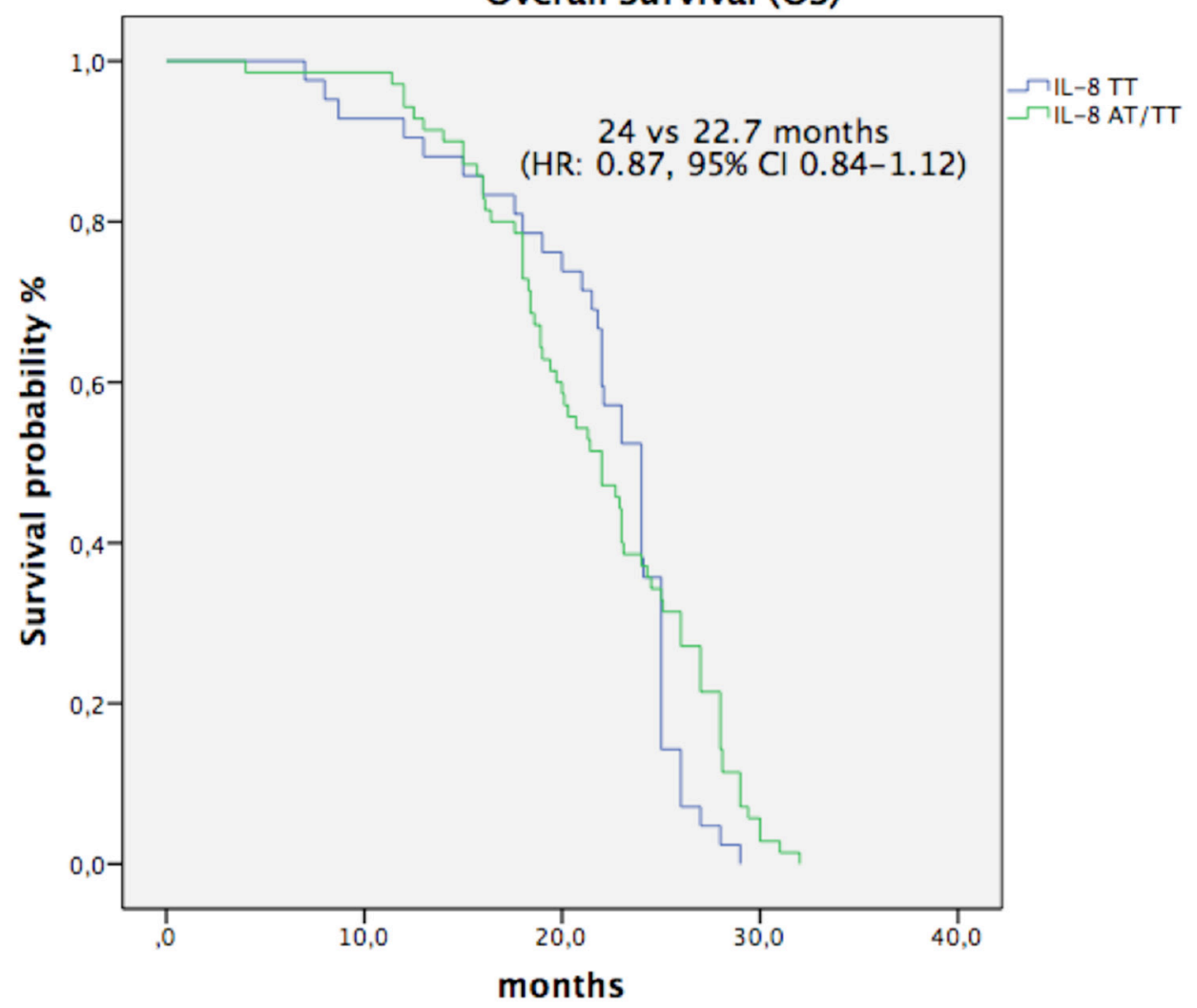

Figure 2: A-B. Kaplan-Meier plots for PFS (A) and OS (B) in control group patients with IL-8 TT genotype versus heterozygous TA and polymorphic homozygous AA genotypes. 
Table 3: Association of bevacizumab-related specific toxicity and candidate SNPs

\begin{tabular}{|c|c|c|}
\hline SNPs & $\%$ & $\mathbf{P}$ \\
\hline \multicolumn{3}{|l|}{ IL-8 -251 T>A } \\
\hline TT+TA vs AA (recessive model) & 14 vs 11.5 & 1 \\
\hline TT vs TA+AA (dominant model) & 22 vs 10 & 0.06 \\
\hline \multicolumn{3}{|l|}{ eNOS -786 T>C } \\
\hline TT + TC vs CC (recessive model) & 12 vs 21 & 0.22 \\
\hline TT vs TC $+\mathrm{CC}$ (dominant model) & 12 vs 15 & 0.77 \\
\hline \multicolumn{3}{|l|}{ eNOS -894 G>T } \\
\hline GG+GT vs TT (recessive model) & $8 v s 50$ & 0.0002 \\
\hline GG vs GT+TT (dominant model) & $5 v s 18$ & 0.04 \\
\hline \multicolumn{3}{|l|}{ VEGF-A c. $936 C>T$} \\
\hline $\mathrm{CC}+\mathrm{CT}$ vs TT (recessive model) & 10 vs 11 & 0.93 \\
\hline $\mathrm{CC}$ vs $\mathrm{CT}+\mathrm{TT}$ (dominat model) & 9.5 vs 10 & 0.98 \\
\hline \multicolumn{3}{|l|}{ VEGF-A c. $958 \mathrm{C}>\mathrm{T}$} \\
\hline CC + CT vs TT (recessive model) & 9 vs 12 & 0.73 \\
\hline $\mathrm{CC}$ vs CT + TT (dominat model) & 8.5 vs 10 & 0.88 \\
\hline \multicolumn{3}{|l|}{ VEGF-A c. $1154 \mathrm{~A}>\mathrm{G}$} \\
\hline $\mathrm{AA}+\mathrm{AG}$ vs GG (recessive model) & 8 vs 9 & 0.92 \\
\hline AA vs AG + GG (dominat model) & 10.5 vs 10 & 0.98 \\
\hline \multicolumn{3}{|l|}{ VEGF-A c. $2578 \mathrm{C}>\mathrm{A}$} \\
\hline $\mathrm{CC}+\mathrm{CA}$ vs AA (recessive model) & 8 vs 8 & 1 \\
\hline $\mathrm{CC}$ vs $\mathrm{CA}+\mathrm{AA}$ (dominat model) & 9 vs 11 & 0.88 \\
\hline
\end{tabular}

Relationship of polymorphisms with toxicity (hypertension and proteinuria).

Italic and bold: statistical significant value.

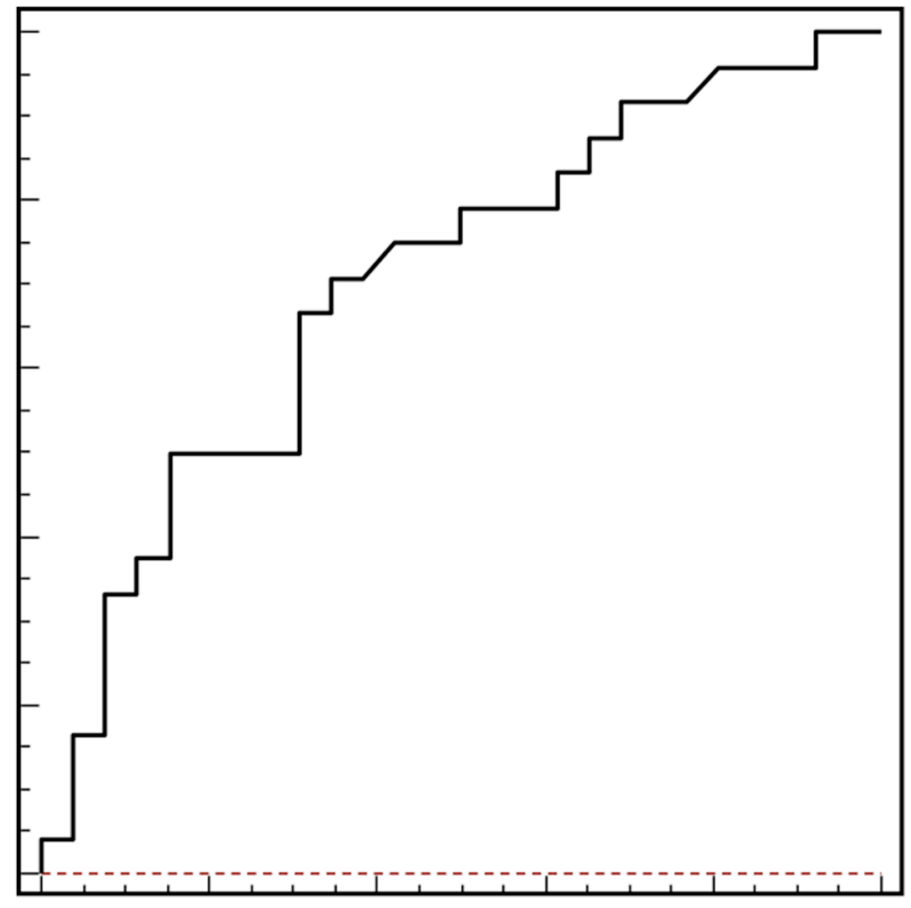

Figure 3: Receiver operating characteristics (ROC) curve analysis based on pre-treatment IL-8 serum levels. In this model sensitivity was $80 \%$ (95\% CI: 74.7-82.8) and specificity was 56\% (95\% CI: 51.9-79.1). Area under the curve was 0.71 , P=0.004. 
( $\mathrm{P}=0.01)$, but not with OS. This apparent discrepancy is not surprising, since PFS is widely accepted as a surrogate endpoint in first-line treatment, due to dilution of effects on OS by post-progression treatments. Similar observations on this IL-8 SNP were recently shown in patients with breast cancer treated with bevacizumabbased chemotherapy $[27,28]$ and in exudative macular degeneration after bevacizumab treatment [29]. Since the "A" allele of the IL-8 SNP is associated with increased IL-8 production [11], a plausible biological explanation of our results is that patients carrying the A allele might benefit less from bevacizumab because of higher IL-8 serum levels. In support of the role of IL-8 as factor of resistance to bevacizumab in metastatic colorectal cancer patients, a better clinical outcome was reported when IL-8 baseline levels were lower [30, 31]. On the contrary, Kopetz et al. showed that high IL-8 levels were associated with a shorter PFS and increased tumor volume [32]. In our study, we confirm that higher IL-8 serum levels were associated with shorter PFS and OS. Moreover, we demonstrate for the first time the functional effect of IL-8 c.-251T > A SNP in cancer patients. In fact, we showed a statistically significant correlation between the polymorphic "A" allele and higher IL-8 serum levels, achieving the proof-of-concept that IL-8 might play a key role in the intrinsic resistance to bevacizumab in mCRC. Since the presence of polymorphic "A" allele did not influence IL-8 serum levels in healthy volunteers, we hypothesize that the pro-inflammatory state caused by the metastatic process may enhance IL- 8 transcription in genetically predisposed patients. The genetic variation may also drive treatment-acquired resistance due to IL8-driven pro-inflammatory switch. In this scenario, IL-8 may represent not only a prognostic biomarker in patients treated with anti-angiogenic therapy, but also a therapeutic target.

Regarding the eNOS gene, preclinical studies showed that eNOS c.-894G $>\mathrm{T}$ variant has a functional effect on eNOS protein, leading to a reduced NO production [17]. Recently, Ulivi et al. found that eNOS c.-894GT polymorphism may also predict efficacy of bevacizumab based-therapy in mCRC [33]. In our study, the multivariate analysis seemed to exclude a potential impact of eNOS on efficacy outcomes. However, we also focused on toxicity and showed that eNOS c.-894TT genotype was associated with significantly higher rate of grade 3-4 hypertension and proteinuria as compared to others. It must be pointed out that potential bevacizumabspecific toxicities can be serious and contraindicate the use of this agent in patients at risk. Not surprisingly, alteration in the eNOS pathway may be correlated with the most frequent toxicities of bevacizumab, such as hypertension and proteinuria [34, 35]. In this context, in patients carrying eNOS c.-894 polymorphic " $\mathrm{T}$ " allele, lower basal levels of eNOS may increase the risk of hypertension induced by VEGF blockade [36-38].
Despite the biological consistency of our results, our study is limited by small sample size and retrospective evaluation. Therefore, it should be considered only as exploratory study. However, the absence of prognostic impact of IL-8 SNPs in the control group, allow to formulate the hypothesis that this factor may be a predictor of efficacy to bevacizumab-based treatment. However, the study of polymorphisms in alternative pathways of angiogenesis affords an original cue for future research on biomarkers predictive for bevacizumab activity and toxicity and may open the way to anti-IL-8 strategies to overcome primary or acquired resistance to bevacizumab in selected patients.

\section{MATERIALS AND METHODS}

\section{Patients selection}

This study was conducted at two Italian Institutions: the cohort 1 comprised 70 patients treated at Policlinico "A. Gemelli" of Rome; the cohort 2 comprised 50 patients treated at Fondazione IRCSS Istituto Nazionale dei Tumori of Milan. Both cohorts included only $R A S$ mutated patients treated with first-line combination of FOLFOX6 plus bevacizumab (bevacizumab group). The study was approved by the local Ethics Committee and written informed consent was required before study procedures. Main inclusion criteria were: histologically confirmed diagnosis of $\mathrm{mCRC}$, age $\geq 18$ years, presence of at least one measurable lesion according to RECIST 1.0 , no prior treatments for metastatic disease, ECOG performance status between 0 and 2 , and acceptable bone marrow, liver and renal functions. We excluded patients with serious concomitant illness that could affect the treatment outcome or survival. Treatment was continued until disease progression, occurrence of unacceptable toxicity or consent withdrawal. A historical cohort of 112 RAS mutated patients treated at Policlinico "A. Gemelli", from January 2002 until November 2007, with first-line FOLFOX alone served as control group.

\section{Single nucleotide polymorphisms genotyping}

The following SNPs were analysed: IL-8 c.251T $>$ A; eNOS c.-786T $>$ C and c.-894G $>$ T; VEGF-A c. $936 \mathrm{C}>\mathrm{T}, \quad$ c. $958 \mathrm{~T}>\mathrm{C}, \quad$ c. $1154 \mathrm{~A}>\mathrm{G}$ and $\quad$ c. $2578 \mathrm{C}>\mathrm{A}$. Given their promising results, IL-8 and eNOS SNPs were analyzed in the whole series. VEGF SNPs were explored exclusively in cohort 1 and, given the non significant results in this training set, further analyses on the whole series was abandoned. Blood samples were stored at $-20^{\circ} \mathrm{C}$ and used for molecular analyses. DNA wasi extracted with Maxwell (R) 16 System from Promega (Madison, USA), using a specific kit (AS1010-Maxwell 16 Blood DNA purification kit) that allows the simultaneous extraction of DNA from 16 blood samples. Samples were analysed 
using the polymerase chain reaction-restriction fragment length polymorphism (PCR-RFLP) technique. Once extracted, DNA from each sample was amplified by PCR with primers specific for each SNP. PCR products were digested by restriction enzymes (FastDigest $\AA$ Restriction Enzymes, Fermentas, USA) specific for each polymorphism. The fragments obtained from each cut were then separated on the basis of molecular weight by electrophoresis on 3\% agarose gel in 1x TAE buffer (40 $\mathrm{mM}$ tris [pH 7.6], $20 \mathrm{mM}$ acetic acid and $1 \mathrm{mM}$ EDTA), colored with ethidium bromide and visualized with ultraviolet light. The genotyping analysis was performed by laboratory personnel and patient clinical outcomes were blinded to laboratorists.

\section{IL-8 serum levels quantification}

Pre-treatment serum samples were available only for patients in cohort 2. IL-8 levels were quantified by ELISA, with the use of a Quantikine ELISA Human CXCL8/IL-8 Immunoassay kit (R\&D Systems a biotechne brand, Minneapolis, MN), according to the manufacturer's protocol.

\section{Statistical analysis}

All polymorphisms were examined for deviation from Hardy-Weinberg equilibrium (HWE) by comparing actual allelic distributions with those expected from HWE using a $\chi 2$-test. No formal statistical hypothesis testing neither adjustment for multiple comparison were performed because this study was exploratory in nature and aimed to generate hypothesis for future studies. Therefore, only descriptive statistics were derived. Progression free survival (PFS) was defined as the time from treatment start to progressive disease (PD) or death. Overall survival (OS) was defined as the time from treatment start to death or last follow up. Overall response rate (ORR) was evaluated by RECIST version 1.0 criteria and tumor assessments were repeated every 12 weeks until PD. Bevacizumab-related toxicities were assessed at each cycle according to National Cancer Institute Common Toxicity Criteria (version 3.0). The association between each gene polymorphism with response and toxicity was evaluated by Fisher's exact test. The Kaplan-Meier method and log-rank test were used to estimate the role of each variable in predicting the hazard ratio (HR) for disease progression and death. Clinical variables including: age ( $\leq 65$ vs $>65)$, histology (mucinous versus non-mucinous), primary site, ECOG performance status (0-1 vs 2 ), number of metastatic sites $(\leq 2$ vs $>2$ ) and previous adjuvant treatment. The correlation of clinical characteristics and SNP status with survival was assessed in univariate analyses according to the dominant and recessive genetic models. Cox proportional hazard model was adopted in the multivariate analysis, including as covariates variables significantly correlated with survival in the univariate analyses $(\mathrm{P}<0.05)$. Receiver operating characteristics (ROC) curve analysis was performed to determine a cutoff value for pre-treatment IL-8 levels using median PFS as endpoint. The Kruskal-Wallis test was used to correlate IL-8 serum levels with SNP -251 T/A. All analyses were two-sided, and statistical significance was defined by a $\mathrm{P}$ value of $<0.05$. Analyses were performed using SPSS for MAC (version 22.0.0).

\section{Abbreviations}

IL-8: Interleukine 8; mCRC: metastatic colorectal cancer; ORR: Overall response rate; OS: Overall Survival; PD: Progression disease; PFS: Progression free survival; SNPs: single nucleotide polymorphisms; VEGF: vascular endothelial growth factor.

\section{CONFLICTS OF INTEREST}

The authors declare no conflicts of interest.

\section{REFERENCES}

1. Giuliano S, Pagès G. Mechanisms of resistance to antiangiogenesis therapies. Biochimie 2013 95:1110-1119.

2. Jubb AM, Hurwitz HI, Bai W, Holmgren EB, Tobin P, Guerrero AS, Kabbinavar F, Holden SN, Novotny WF, Frantz GD, Hillan KJ, Koeppen H. Impact of vascular endothelial growth factor-A expression, thrombospondin-2 expression, and microvessel density on the treatment effect of bevacizumab in metastatic colorectal cancer. J Clin Oncol. 2006 24:217-227.

3. Jubb AM, Harris AL. Biomarkers to predict the clinical efficacy of bevacizumab in cancer. Lancet Oncol 2010 11:1172-1183.

4. Pietrantonio F, Orlandi A, Inno A, Da Prat V, Spada D, Iaculli A, Di Bartolomeo M, Morosi C, de Braud F. Bevacizumab-based neoadjuvant chemotherapy for colorectal cancer liver metastases: Pitfalls and helpful tricks in a review for clinicians. Crit Rev Oncol Hematol. 2015 95:272-281.

5. Loupakis F, Ruzzo A, Salvatore L, Cremolini C, Masi G, Frumento P, Schirripa M, Catalano V, Galluccio N, Canestrari E, Vincenzi B, Santini D, Bencardino $\mathrm{K}$, et al. Retrospective exploratory analysis of VEGF polymorphisms in the prediction of benefit from first-line FOLFIRI plus bevacizumab in metastatic colorectal cancer. BMC Cancer. 2011 11:247.

6. Loupakis F, Cremolini C, Yang D, Salvatore L, Zhang W, Wakatsuki T, Bohanes P, Schirripa M, Benhaim L, Lonardi S, Antoniotti C, Aprile G, Graziano F, et al. Prospective 
validation of candidate SNPs of VEGF/VEGFR pathway in metastatic colorectal cancer patients treated with first-line FOLFIRI plus bevacizumab. PLoS One. 2013 8:e66774.

7. Koch AE, Polverini PJ, Kunkel SL, Harlow LA, DiPietro LA, Elner VM, Elner SG, Strieter RM. Interleukin-8 as a macrophage-derived mediator of angiogenesis. Science. 1992 258:1798-1801.

8. Varney ML, Olsen KJ, Mosley RL, Bucana CD, Talmadge JE, Singh RK. Monocyte/macrophage recruitment, activation and differentiation modulate interleukin-8 production: a paracrine role of tumor-associated macrophages in tumor angiogenesis. In Vivo. 2002 16:471-477.

9. Mizukami Y1, Jo WS, Duerr EM, Gala M, Li J, Zhang X, Zimmer MA, Iliopoulos O, Zukerberg LR, Kohgo Y, Lynch MP, Rueda BR, Chung DC. Induction of interleukin-8 preserves the angiogenic response in HIF-1alpha-deficient colon cancer cells. Nat Med 2005 11:992-997.

10. Martin D, Galisteo R, Gutkind JS. CXCL8/IL8 stimulates vascular endothelial growth factor (VEGF) expression and the autocrine activation of VEGFR2 in endothelial cells by activating NFkappaB through the CBM (Carma3/Bcl10/ Malt1) complex. J Biol Chem 2009. 284:6038-6042

11. Hull J, Thomson A, Kwiatkowski D. Association of respiratory syncytial virus bronchiolitis with the interleukin 8 gene region in UK families. Thorax 2000 55:1023-1027.

12. Ohyauchi M, Imatani A, Yonechi M, Asano N, Miura A, Iijima K, Koike T, Sekine H, Ohara S, Shimosegawa T. The polymorphism interleukin $8-251 \mathrm{~A} / \mathrm{T}$ influences the susceptibility of Helicobacter pylori related gastric diseases in the Japanese population. Gut. 2005 54:330-335.

13. Taguchi A1, Ohmiya N, Shirai K, Mabuchi N, Itoh A, Hirooka Y, Niwa Y, Goto H. Interleukin-8 promoter polymorphism increases the risk of atrophic gastritis and gastric cancer in Japan. Cancer Epidemiol Biomarkers Prev. 2005 14:2487-2493.

14. Hildebrand F, Stuhrmann M, van Griensven M, Meier S, Hasenkamp S, Krettek C, Pape HC. Association of IL-8251A/T polymorphism with incidence of acute respiratory distress syndrome (ARDS) and IL-8 synthesis after multiple trauma. Cytokine. 2007 37:192-199.

15. Wang Z, Shao J, Zhou Q, Liu J, Zhu Y, Yang J, Wei M. The -251A. T polymorphism of interleukin- 8 is associated with longer mechanical ventilation and hospital staying after coronary surgery. Cytokine 2010 50:268-272.

16. van der Zee R, Murohara T, Luo Z, Zollmann F, Passeri J, Lekutat C, Isner JM. Vascular endothelial growth factor/ vascular permeability factor augments nitric oxide release from quiescent rabbit and human vascular endothelium. Circulation. 1997 95:1030-1037.

17. Hood JD, Meininger CJ, Ziche M, Granger HJ. VEGF upregulates eNOS message, protein, and NO production in human endothelial cells. Am J Physiol. 1998 274:H1054-H1058.
18. Ziche M, Parenti A, Ledda F, Dell'Era P, Granger HJ, Maggi CA, Presta M. Nitric oxide promotes proliferation and plasminogen activator production by coronary venular endothelium through endogenous bFGF. Circ Res. 1997. 80:845-852.

19. Dimmeler S, Hermann C, Galle J, Zeiher AM. Upregulation of superoxide dismutase and nitric oxide synthase mediates the apoptosis suppressive effects of shear stress on endothelial cells. Arterioscler Thromb Vasc Biol. 1999. 19:656-664.

20. Rössig L, Fichtlscherer B, Breitschopf K, Haendeler J, Zeiher AM, Mülsch A, Dimmeler S. Nitric oxide inhibits caspase-3 by S-nitrosation in vivo. J Biol Chem. 1999. 274:6823-6826.

21. Dulak J1, Józkowicz A, Dembinska-Kiec A, Guevara I, Zdzienicka A, Zmudzinska-Grochot D, Florek I, Wójtowicz A, Szuba A, Cooke JP. Nitric oxide induces the synthesis of vascular endothelial growth factor by rat vascular smooth muscle cells. Arterioscler Thromb Vasc Biol. 2000. 20:659-666.

22. Eechoute K, van der Veldt AA, Oosting S, Kappers MH, Wessels JA, Gelderblom H, Guchelaar HJ, Reyners AK, van Herpen CM, Haanen JB, Mathijssen RH, Boven E. Polymorphisms in endothelial nitric oxide synthase (eNOS) and vascular endothelial growth factor (VEGF) predict sunitinib-induced hypertension. Clin Pharmacol Ther. 2012. 92:503-510.

23. Schneider BP, Gray RJ, Radovich M, Shen F, Vance G, Li L, Jiang G, Miller KD, Gralow JR, Dickler MN, Cobleigh MA, Perez EA, Shenkier TN, et al. Prognostic and Predictive Value of Tumor VEGF Gene Amplification in Metastatic Breast Cancer Treated With Paclitaxel With and Without Bevacizumab; Results From ECOG 2100 Trial. Clin Cancer Res. 2013. 19:1281-1289.

24. Kaitlyn K.H. Goey, Sjoerd G. Elias, Harm van Tinteren, Miangela M. Lacle, Stefan M. Willems, Wendy W.J. de Leng, Eric Strengman, Celien Vreuls, Geert-Jan Creemers, Ankie Van Der Velden, Cornelis J. A. Punt, Miriam Koopman. Predictive value of KRAS mutation status in metastatic colorectal cancer ( $\mathrm{mCRC}$ ) patients treated with capecitabine and bevacizumab (CAP-B) maintenance treatment vs observation in the phase III CAIRO3 study. J Clin Oncol 34, 2016 (suppl; abstr 3525)

25. Kubicka S, Greil R, André T, Bennouna J, Sastre J, Van Cutsem E, von Moos R, Osterlund P, Reyes-Rivera I, Müller T, Makrutzki M, Arnold D. Bevacizumab plus chemotherapy continued beyond first progression in patients with metastatic colorectal cancer previously treated with bevacizumab plus chemotherapy: ML18147 study KRAS subgroup findings. Ann Oncol. 2013. 24:2342-9.

26. Huang D1, Ding Y, Zhou M, Rini BI, Petillo D, Qian CN, Kahnoski R, Futreal PA, Furge KA, Teh BT. Interleukin-8 mediates resistance to antiangiogenic agent sunitinib in renal cell carcinoma. Cancer Res. 2010. 70:1063-1071. 
27. Allegrini G1, Coltelli L, Orlandi P, Fontana A, Camerini A, Ferro A, Cazzaniga M, Casadei V, Lucchesi S, Bona E, Di Lieto M, Pazzagli I, Villa F, et al. Pharmacogenetic interaction analysis of VEGFR-2 and IL-8 polymorphisms in advanced breast cancer patients treated with paclitaxel and bevacizumab. Pharmacogenomics. 2014. 15:1985-1999.

28. Di Salvatore M, Lo Giudice L, Rossi E, Santonocito C, Nazzicone G, Rodriquenz MG, Cappuccio S, Inno A, Fuso P, Orlandi A, Strippoli A, Capoluongo E, Astone A, et al. Association of IL-8 and eNOS polymorphisms with clinical outcomes in bevacizumab-treated breast cancer patients: an exploratory analysis. Clin Transl Oncol. 2015.

29. Hautamäki A, Kivioja J, Vavuli S, Kakko S, Savolainen ER, Savolainen MJ, Liinamaa MJ, Seitsonen S, Onkamo P, Järvelä I, Immonen I. Interleukin 8 promoter polymorphism predicts the initial response to bevacizumab treatment for exudative age-related macular degeneration. Retina. 2013. 33:1815-1827.

30. Bünger S, Haug U, Kelly FM, Klempt-Giessing K, Cartwright A, Posorski N, Dibbelt L, Fitzgerald SP, Bruch HP, Roblick UJ, von Eggeling F, Brenner H, Habermann JK, et al. Toward standardized high-throughput serum diagnostics: multiplex-protein array identifies IL-8 and VEGF as serum markers for colon cancer. J Biomol Screen, 2011. 16:1018-1026.

31. Abajo A, Boni V, Lopez I, Gonzalez-Huarriz M, Bitarte N, Rodriguez J, Zarate R, Bandres E, Garcia-Foncillas $\mathrm{J}$. Identification of predictive circulating biomarkers of bevacizumab-containing regimen efficacy in pre-treated metastatic colorectal cancer patients. Br J Cancer. 2012. 107:287-290.
32. Kopetz S1, Hoff PM, Morris JS, Wolff RA, Eng C, Glover KY, Adinin R, Overman MJ, Valero V, Wen S, Lieu C, Yan $\mathrm{S}$, Tran HT, et al. Phase II trial of infusional fluorouracil, irinotecan, and bevacizumab for metastatic colorectal cancer: efficacy and circulating angiogenic biomarkers associated with therapeutic resistance. J Clin Oncol. 2010. 28:453-459.

33. Ulivi P, Scarpi E, Passardi A, Marisi G, Calistri D, Zoli W, Del Re M, Frassineti GL, Tassinari D, Tamberi S, Vertogen B, Amadoriet B, et al. eNOS polymorphisms as predictors of efficacy of bevacizumab-based chemotherapy in metastatic colorectal cancer: data from a randomized clinical trial. J Transl Med. 2015. 13:258.

34. Mohan S, Reddick RL, Musi N, Horn DA, Yan B, Prihoda TJ, Natarajan M ; Abboud-Werner SL. Diabetic eNOS knockout mice develop distinct macro- and microvascular complications. Lab Invest. 2008. 88:515-528.

35. Ott C, Schneider MP, Delles C, Schlaich MP, Schmieder RE. Reduction in basal nitric oxide activity causes albuminuria. Diabetes. 2011. 60:572-576.

36. Ando M. [Nephrotoxicity—-proteinuria and hypertension- ]. Gan To Kagaku Ryoho. 2008. 35:1649-1653.

37. Pande A, Lombardo J, Spangenthal E, Javle M. Hypertension Secondary to Anti-angiogenic Therapy: Experience with Bevacizumab. Anticancer Res. 2007. 27:3465-3470.

38. Shubhangi A, Nibhriti D, Kamna S. Nitric Oxide and eNOS Gene in Essential Hypertension. International. Journal of Collaborative Research on Internal Medicine \& Public Health 2009. Vol. 1 No. 2 Pages 56-71. 